Vanredni profesor dr Vlado Đurković,

dipl. inž.

Vojna akademija,

Beograd
METODOLOGIJA POSTAVLJANJA DIFERENCIJALNIH JEDNAČINA PRI ISTRAŽIVANJU DINAMIČKIH PARAMETARA KONSTRUKCIJE LANSIRNE RAMPE NA VOZILU TOČKAŠU

UDC: $623.428 .2 .01: 623.437 .448 .01$

Rezime:

U radu se određuju optimalni parametri konstrukcije lansirne rampe: položaj tačke vešanja hidrocilindra na rampi, dužina i materijal rampe, koeficijent viskoznog trenja ulja $u$ hidrocilindru, koeficijent krutosti lansirne rampe i hidrocilindra, poprečni presek rampe, itd. Radi toga postavlja se mehanički model sa tri stepena slobode kretanja i odgovarajući model $u$ vidu sistema od tri nelinearne diferencijalne jednačine drugog reda. Numeričkom analizom dobijenog matematičkog modela (primenom programskog jezika Compaq Visual Fortran, Version 6.5) dolazi se do optimalnosti pojedinih parametara. Dobijeni rezultati, predstavljeni u grafičkoj formi, mogu da budu veoma korisni projektantima raketnih lansera, kako stabilnih, tako i mobilnih, pri razvoju novih konstrukcija i modifikaciji postojećih.

Ključne reči: lansirna rampa, lansiranje, dinamički model, kinetička energija, potencijalna energija, generalisane sile.

\title{
METHODOLOGY MAKE OF DIFERENTIAL EQUATIONS AT INVESTIGATION OF DYNAMIC PARAMETERS OF CONSTRUCTIONS OF LAUNCHER ON VEHICLE
}

Summary:

This paper determines optimal construction parametrics of a missile launcher: place of hydro-cylinder on launcher, length and material of ramp of launcher, coefficient of the viscosity of friction oil in hydro-cylinder, coefficient of stiffness of launcher and hydro-cylinder, cross-section of launcher etc. In this purpose appointment mechanical model with three degrees of freedom motion and analogous model of system of three nonlinear differential equation second order. Numerical analysis obtained mathematical model (programming with language Compaq Visual Fortran, Version 6.5) coming to optimal parameters. Obtained results that are presented in graphical shapes can be very useful for designing stable and mobile missile launchers, both for development of new constructions and modification of existing structures.

Key words: launcher, launching, dynamic model, kinetic energy, potentional energy, generalized forces.

\section{Uvod}

Raketni lanser spada u grupu artiljerijskih oruđa namenjenih za dejstva po živoj sili, ali i po pojedinim utvrđenim tačkama duboko u pozadini neprijatelja. Vojni teoretičari ga, stoga, svrstavaju u grupu artiljerijskih oruđa za podršku sopstvenoj pešadiji.

Osnovni zahtev bezbednog rukovanja objektom, kao što je raketni lanser, pretpostavlja stabilnost posmatranog objekta u odnosu na preturanje, kao i stabilnost njegovih pojedinih elemenata $\mathrm{i}$ 
sklopova, kao što je lansirna rampa. Stabilnost objekta tipa raketnog lansera ili auto-dizalice sa aspekta preturanja razmatrana je u radovima $[3,4,5,7,8,9]$ primenom mehaničko-matematičkog modela različitih stepena složenosti. Eksperimentalno utvrđivanje pomeranja elastično oslonjenog rama vozila u uslovima impulsnog opterećenja, i analiza elastično oslonjenog rama vozila sa nadgradnjom, razmatrana je u radovima $[11,12]$.

Osnovna prednost predloženog modela raketnog lansera u odnosu na postojeće modele sastoji se u tome što se pri razmatranju stabilnosti analiziranog sistema uzima u obzir uticaj nekoliko ranije zanemarivanih parametara: elastičnost i prigušenje oslonca, rampe, elastičnost lansirne rampe.

\section{Mehanički model}

Mehanički model lansirne rampe sa raketom $\mathrm{u}$ toku njenog lansiranja (slika 1) koji se predlaže sastoji se od krutih tela, deformabilnih elemenata sa elastičnim osloncem sa prigušenjem.

Ovakav mehanički sistem sastoji se od lansirne rampe deformabilne u vertikalnoj ravni i deformabilne oko uzdužne ose Ax, oslonjene zglobno $\mathrm{u}$ osloncu $\mathrm{A}$ i elastično $\mathrm{u}$ osloncu B i od raketa koje se smatraju krutim telima. Kretanje takvog mehaničkog sistema definisano je sledećim generalisanim koordinatama: $\xi$ - pomeranje rakete po deformabilnoj lansirnoj rampi, u - ugib vrha lansirne rampe, pri čemu se svi ostali ugibi duž rampe $\left(\mathrm{u}_{\mathrm{x}}\right)$ izražavaju $\mathrm{u}$ funkciji ovog ugiba, $\varphi$ - ugao rotacije rampe oko uzdužne ose rampe Ax usled asimetričnosti opterećenja, posebno nakon pojedinačnog lansiranja raketa (razmatra se slučaj kretanja jedne rakete po rampi, dok ostale dve miruju).

Jednačina elastične linije lansirne rampe je nepoznata. U radovima koji su obrađivali problem dinamičke stabilnosti strele auto-dizalice [3] i radovima po pitanju raketnog lansera $[1,2,5,6,10]$ predlagane su različite funkcije elastičnih linija, na primer, trigonometrijske funkcije ili polinomi. U ovom radu elastična linija lansirne rampe, zbog šest graničnih uslova, ima oblik polinoma:

$$
\begin{aligned}
& y=f(x)=a_{0}+a_{1} x+a_{2} x^{2}+ \\
& +a_{3} x^{3}+a_{4} x^{4}+a_{5} x^{5}=\sum_{i=0}^{5} a_{i} x^{i}
\end{aligned}
$$

Uslovi koje treba da zadovolji kriva oblika oscilovanja su:

- prva dva granična uslova: tačka A, zglobni oslonac $\mathrm{O} \equiv \mathrm{A}, \mathrm{x}=0$

$y(0)=0$ (ugib zgloba jednak je nuli),

$y^{\prime \prime}(0)=0$ (zglob ne prima momenat);

- druga dva granična uslova: tačka B, zglobni oslonac B je elastičan $[1,3]$, pa je transverzalna sila jednaka sili elastičnosti hidrocilindra.

$x=x_{B} F_{t B}=F_{C}=E I_{z} y^{\prime \prime \prime}\left(x_{B}\right)=$

$=-c y\left(x_{B}\right) \cos \theta-b \dot{y}_{B} \cos \theta$

$y^{\prime \prime}\left(l_{1}\right)=0, M_{s}=0, y^{\prime \prime}\left(x_{B}\right)=0$

- treća dva granična uslova: tačka D, $\mathrm{x}=\mathrm{x}_{\mathrm{D}}=1$,

$M_{s}=0,\left(y^{\prime \prime}(l)=0\right)$ (vrh strele ne prima moment),

$F_{t}=0,\left(y^{\prime \prime \prime}(l)=0\right)($ vrh strele ne prima transverzalnu silu) 


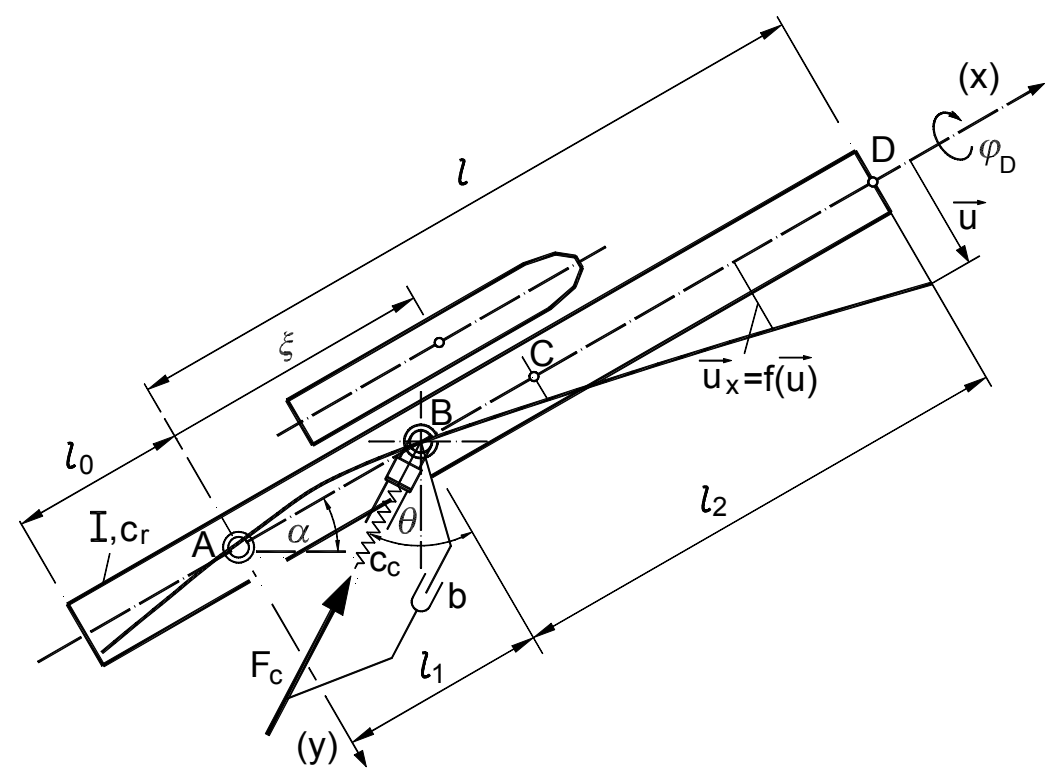

Sl. 1 - Mehanički model lansirne rampe

Koeficijenti polinoma su:

$a_{0}=a_{2}=a_{3}=a_{4}=a_{5}=0$,

$a_{1}=-\frac{b \dot{y}_{B}}{c l_{1} \cos \theta}=$ const.

pa je kriva oblika oscilovanja u konačnom obliku:

$y=a_{1} x=-\frac{b \dot{y}}{c l_{1} \cos \theta} \cdot x$

gde su:

$1_{1}$ - geometrijska karakteristika lansirne rampe (sl. 1),

$\mathrm{x}$ - koordinata duž lansirne rampe,

$\mathrm{b}$ - koeficijent viskoznog trenja u hidrocilindru,

c - krutost oslonca B (hidrocilindra), $\dot{y}-$ brzina tačke vešanja hidrocilindra.

\section{Sila u hidrocilindru}

U ovom radu sila u hidrocilindru, prema [2], iznosi:

$F_{C}=l_{1} c\left(\varphi_{s t}+\varphi_{d i}\right)+l_{1} \dot{\varphi} b=$

$=l_{1} c\left(\varphi_{s t}+\varphi_{d i}\right)+\frac{l_{1}}{l} \dot{u} b=f(u, \dot{u}, \ldots)$

gde su $u=l \varphi, \varphi=\frac{u}{l}, \dot{\varphi}=\frac{\dot{u}}{l}$

\section{Kinetička energija mehaničkog sistema}

Kinetička energija lansirne rampe sa raketom iznosi:

$E_{k}=E_{k 1}+E_{k 2}$

gde su:

$\mathrm{E}_{\mathrm{k} 1}$ - kinetička energija lansirne rampe, $\mathrm{E}_{\mathrm{k} 2}-$ kinetička energija rakete. 


\section{Kinetička energija lansirne rampe}

Kinetička energija lansirne rampe sastoji se od kinetičke energije lansirne rampe usled savijanja, istezanja - pritiska i kinetičke energije usled torzije lansirne rampe, tj.:

$$
E_{k 1}=E_{k 1}^{(1)}+E_{k 1}^{(2)}+E_{k 1}^{(3)}
$$

- $\mathrm{E}_{\mathrm{k} 1}^{(1)}$ - kinetička energija elastične deformacije lansirne rampe usled savijanja, ne uzimajući u obzir smicanje, jeste:

$$
\begin{aligned}
& E_{k 1}^{(1)}=\frac{1}{2} \rho A \int_{0}^{l} \dot{y}^{2} d x=\frac{1}{2} \rho A \int_{0}^{l}\left(\frac{1}{l^{2}} \dot{u}^{2} x^{2}\right)^{2} \\
& d x=\frac{1}{2} \rho A \frac{\dot{u}^{2}}{l^{2}} \frac{l^{3}}{3}=\frac{l}{6} \rho A \dot{u}^{2}=C_{11} \dot{u}^{2}
\end{aligned}
$$

gde je: $C_{11}=\frac{1 \rho A}{6}-$ odgovarajuća konstanta.

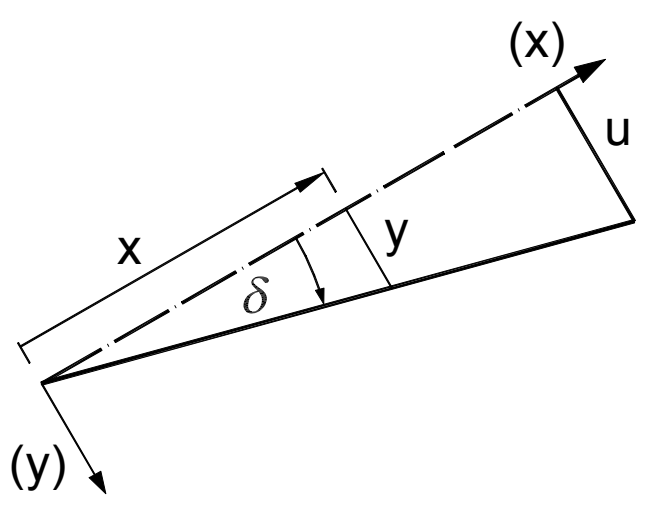

Sl. 2 - Određivanje zavisnosti ugiba i brzina na osnovu proporcije

- $E_{\mathrm{k} 1}^{(2)}$ - kinetička energija elastične deformacije lansirne rampe usled istezanja - pritiska je:

$$
\begin{aligned}
& E_{k 1}^{(2)}=\frac{1}{2} \rho I \int_{0}^{l}\left(\frac{\partial \dot{y}}{\partial x}\right)^{2} d x=\frac{\rho r_{0}^{2} A}{2} \int_{0}^{l} \frac{4 \dot{u}^{4}}{l^{4}} x^{2} d x= \\
& =2 \rho r_{0}^{2} A \frac{\dot{u}^{4}}{l^{4}} \frac{l^{3}}{3}=C_{12} \dot{u}^{4}
\end{aligned}
$$

gde su: $\mathrm{I}_{0}=\mathrm{r}_{0}^{2} \mathrm{~A}$ moment inercije poprečnog preseka u odnosu na neutralnu osu, $r_{0}$ poluprečnik inercije poprečnog preseka u odnosu na neutralnu osu, $\mathrm{C}_{12}=\frac{2 \rho \mathrm{r}_{0}^{2} \mathrm{~A}}{2 \mathrm{l}}$ odgovarajuća konstanta.

- $\mathrm{E}_{\mathrm{k} 1}^{(3)}$ - kinetička energija rampe usled torzionog pomeranja - okretanja $\varphi_{\mathrm{D}}$ oko uzdužne ose Ax, prema [1] je:

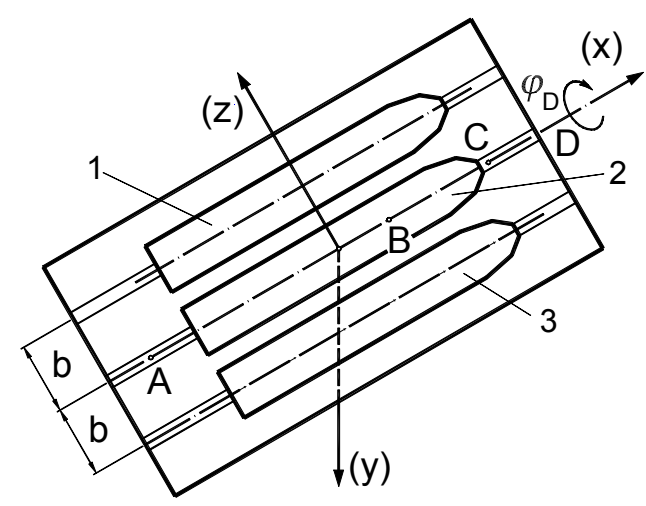

Sl. 3 - Položaj raketa različitih masa $i$ karakterističnih tačaka na rampi

$$
E_{k 1}^{(3)}=\frac{1}{2} I_{O} \dot{\varphi}^{2}
$$

$$
E_{k 1}^{(3)}=\frac{1}{2} \int_{0}^{l} I_{O} \dot{\varphi}_{D}^{2} d x=\frac{1}{2} I_{O} \int_{0}^{l} \frac{\dot{\varphi}_{D}^{2}}{l^{2}} x^{2} d x=
$$

$=\frac{I_{O} \dot{\varphi}_{D}^{2}}{2 l^{2}} \cdot \frac{l^{3}}{3}=C_{13} \dot{\varphi}_{D}^{2}$ 


$$
K_{13}=\frac{I_{O} l}{6}
$$

gde su: $\mathrm{I}_{\mathrm{O}}$ - moment inercije mase rampe po jedinici dužine, tj. $\mathrm{I}_{\mathrm{O}}=\rho \mathrm{I}_{\mathrm{O}}^{\prime}, \rho$-gustina rampe, $I_{O}^{\prime}$ - geometrijski polarni moment poprečnog preseka rampe, $\mathrm{C}_{13}=\frac{\mathrm{I}_{\mathrm{O}} 1}{6}-$ konstanta.

Konačno, kinetička energija lansirne rampe je:

$$
\begin{aligned}
& E_{k 1}=E_{k 1}^{(1)}+E_{k 1}^{(2)}+E_{k 1}^{(3)}=C_{11} \dot{u}^{2}+ \\
& +C_{12} \dot{u}^{4}+C_{13} \dot{\varphi}_{D}^{2}
\end{aligned}
$$

\section{Kinetička energija rakete na lansirnoj rampi}

Kinetička energija rakete sastoji se od kinetičke energije translacije i rotacija rakete na lansirnoj rampi, tj.:

$$
E_{k 2}=E_{k 2}^{(1)}+E_{k 2}^{(2)}+E_{k 2}^{(3)}
$$

gde je: $E_{k 2}^{(1)}$ - kinetička energija rakete od translacije po lansirnoj rampi; $\mathrm{E}_{\mathrm{k} 2}^{(2)}$ - kinetička energija rakete od rotacije zajedno sa lansirnom rampom oko $\mathrm{z}$ ose (sl. 4); $\mathrm{E}_{\mathrm{k} 2}^{(3)}$ - kinetička energija rakete od rotacije zajedno sa lansirnom rampom oko $\mathrm{x}$ ose.
- $\mathrm{E}_{\mathrm{k} 2}^{(1)}$ - kinetička energija rakete od translacije po lansirnoj rampi je:

$$
\begin{aligned}
& E_{k 2}^{(1)}=\frac{1}{2} m_{r} v_{r}^{2}=\frac{1}{2} m_{r} \\
& {\left[\dot{\xi}^{2}+\frac{1}{l^{2}}(\dot{\xi} u+\xi \dot{u})^{2}+\frac{1}{l^{2}}(\dot{\xi} u \varphi+\xi \dot{u} \varphi+\xi u \dot{\varphi})^{2}\right]}
\end{aligned}
$$

gde su:

$$
y=\frac{u}{l} x, \eta=\frac{x}{l}=\frac{\xi}{l}
$$

a za $\eta u=\xi \delta \Rightarrow \delta=\frac{\eta u}{\xi}$, odnosno

$$
\delta=\frac{\xi}{l} \cdot \frac{u}{\xi}=\frac{u_{D}}{l}
$$

radijus-vektor i brzina rakete glase:

$$
\vec{r}_{M}=\xi \cdot \vec{i}+\eta u \cdot \vec{j}+\eta u \cdot \varphi \cdot \vec{k}
$$

$$
\begin{aligned}
& \vec{v}_{r}=\frac{d \vec{r}_{M}}{d t}=\dot{\xi} \cdot \vec{i}+\frac{1}{l}(\dot{\xi} u+\xi \dot{u}) \cdot \vec{j}+ \\
& +\frac{1}{l}\left(\dot{\xi}_{u} \varphi+\xi \dot{u} \varphi+\xi u \dot{\varphi}\right) \cdot \vec{k}
\end{aligned}
$$

$$
\begin{aligned}
& v_{r}^{2}=\dot{\xi}^{2}+\frac{1}{l^{2}}(\dot{\xi} u+\xi \dot{u})^{2}+ \\
& +\frac{1}{l^{2}}(\dot{\xi} u \varphi+\xi \dot{u} \varphi+\xi u \dot{\varphi})^{2}
\end{aligned}
$$

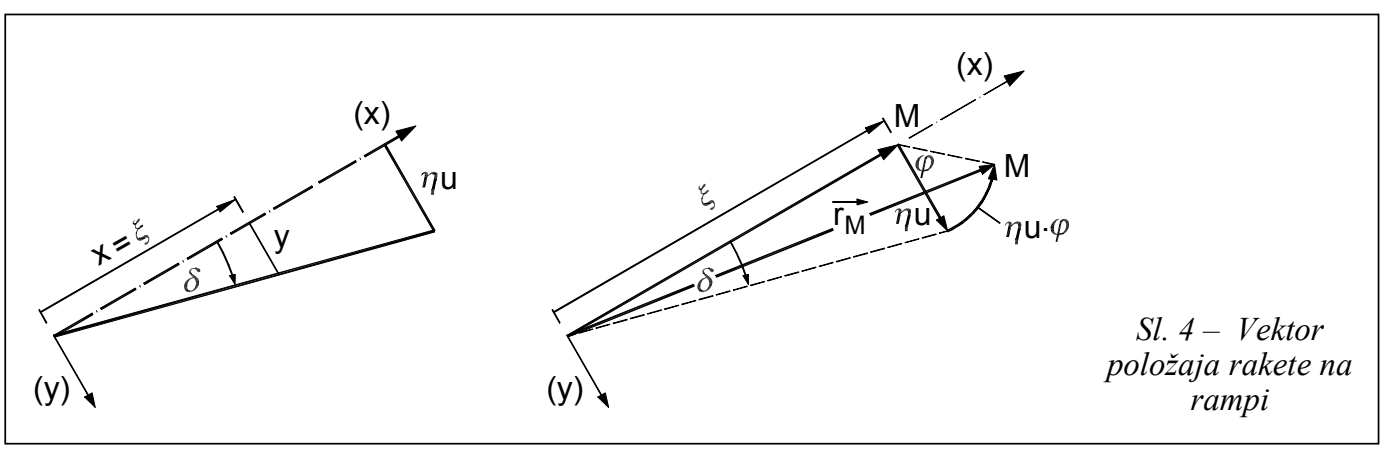


Ako se raketa razmatra kao kruto telo, treba uzeti u obzir i članove od rotacije.

$-E_{\mathrm{k} 2}^{(2)}$ - kinetička energija rakete od rotacije zajedno sa lansirnom rampom oko z ose je:

$$
E_{k 2}^{(2)}=\frac{1}{2} J_{r z} \dot{\delta}^{2}=\frac{1}{2} J_{r z} \frac{\dot{u}_{D}^{2}}{l^{2}}
$$

$-E_{\mathrm{k} 2}^{(3)}$ - kinetička energija rakete od rotacije zajedno sa lansirnom rampom oko $x$ ose je:

$$
E_{k 2}^{(3)}=\frac{1}{2} J_{r x} \dot{\varphi}^{2}
$$

Konačno, kinetička energija rakete je:

$$
\begin{aligned}
& E_{k 2}=\frac{1}{2} m_{r}\left[\begin{array}{l}
\dot{\xi}^{2}+\frac{1}{l^{2}}(\dot{\xi} u+\xi \dot{u})^{2}+\frac{1}{l^{2}} \\
(\dot{\xi} u \varphi+\xi \dot{u} \varphi+\xi u \dot{\varphi})^{2}
\end{array}\right]+ \\
& +\frac{1}{2} J_{r z} \frac{\dot{u}_{D}^{2}}{l^{2}}+\frac{1}{2} J_{r x} \dot{\varphi}^{2}
\end{aligned}
$$

gde su $J_{\mathrm{rz}}$ i $J_{\mathrm{rx}}$ odgovarajući momenti inercije.

Ukupna kinetička energija mehaničkog sistema iznosi:

$$
\begin{aligned}
& E_{k}=E_{k 1}+E_{k 2}=E_{k 1}^{(1)}+E_{k 1}^{(2)}+ \\
& +E_{k 1}^{(3)}+E_{k 2}^{(1)}+E_{k 2}^{(2)}+E_{k 2}^{(3)} \\
& E_{k}=C_{11} \dot{u}^{2}+C_{12} \dot{u}^{4}+C_{13} \dot{\varphi}_{D}^{2}+ \\
& +\frac{m_{r}}{2} \dot{\xi}^{2}+\frac{m_{r}}{2 l^{2}}(\dot{\xi} u+\xi \dot{u})^{2}+ \\
& +\frac{m_{r}}{2 l^{2}}(\dot{\xi} u \varphi+\xi \dot{u} \varphi+\xi u \dot{\varphi})^{2}+\frac{J_{r z}}{2 l^{2}} \dot{u}_{D}^{2}+\frac{J_{r x}}{2} \dot{\varphi}^{2}
\end{aligned}
$$

Potencijalna energija mehaničkog sistema

Potencijalna energija mehaničkog sistema je:

$E_{p}=E_{p 1}+E_{p 2}+E_{p 3}$

gde su: $E_{p 1}$ - potencijalna energija lansirne rampe, $\mathrm{E}_{\mathrm{p} 2}$ - potencijalna energija rakete, $E_{p 3}-$ potencijalna energija oslonca.

\section{Potencijalna energija lansirne rampe}

Potencijalna energija lansirne rampe sastoji se od potencijalne energije elastične deformacije lansirne rampe usled savijanja ne uzimajući u obzir smicanje, potencijalne energije pritiska - istezanja lansirne rampe usled dejstva aksijalnih sila i potencijalne energije lansirne rampe usled dejstva transverzalnih sila, $\mathrm{tj}$. :

$$
E_{p 1}=E_{p 1}^{(1)}+E_{p 1}^{(2)}+E_{p 1}^{(3)}
$$

- $\mathrm{E}_{\mathrm{p} 1}^{(1)}$ - potencijalna energija elastične deformacije lansirne rampe usled savijanja, ne uzimajući u obzir smicanje je:

$$
E_{p 1}^{(1)}=\frac{1}{2} \int_{0}^{l} E I_{1 z}\left(\frac{\partial^{2} y}{\partial x^{2}}\right)^{2} d x=\frac{1}{2} E I_{1 z} \int_{0}^{l} 0=0
$$

- $\mathrm{E}_{\mathrm{p} 1}^{(2)}$ - potencijalna energija pritiska istezanja lansirne rampe usled dejstva aksijalnih sila je: 


$$
\begin{aligned}
& E_{p 1}^{(2)}=\frac{1}{2} \int_{0}^{l} N(x, t)\left(\frac{\partial y}{\partial x}\right)^{2} d x= \\
& =\frac{1}{2} \int_{0}^{l} N(x, t) a_{1}^{2} d x=\frac{a_{1}^{2}}{2} \int_{0}^{l} N(x, t) d x
\end{aligned}
$$

a usled dejstva aksijalnih sila po poljima (deonicama) lansirne rampe je:

$$
\begin{aligned}
& E_{p 1}^{(2)}=\left(E_{p 1}^{(2)}\right)_{1 \text { polje }}+\left(E_{p 1}^{(2)}\right)_{2 \text { polje }}+\left(E_{p 1}^{(2)}\right)_{3 \text { polje }} \\
& E_{p 1}^{(2)}=\frac{a_{1}^{2}}{2}(l-\xi) \rho A g(l-\xi) . \\
& \cdot\left(\sin \alpha-\frac{u}{l} \cos \alpha\right)+
\end{aligned}
$$$$
+\frac{a_{1}^{2}}{2}\left[\rho A g(l-\xi)+m_{2} g\right]
$$$$
\left(\sin \alpha-\frac{u}{l} \cos \alpha\right)\left(\xi-l_{1}\right)+
$$$$
+\frac{a_{1}^{2}}{2}\left[\rho A g(l-\xi)+m_{2} g\right]\left(\sin \alpha-\frac{u}{l} \cos \alpha\right) \text {. }
$$$$
\cdot\left(-c a_{1} l_{1} \sin \theta-b \dot{y}_{B} \sin \theta\right) l_{1}
$$

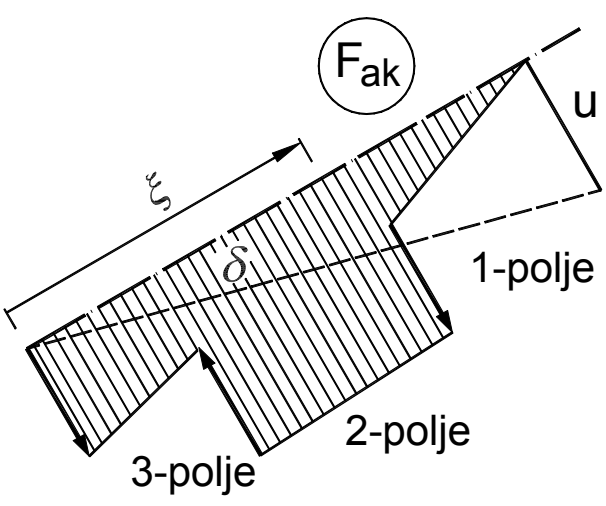

Sl. 5 - Aksijalne sile duž rampe

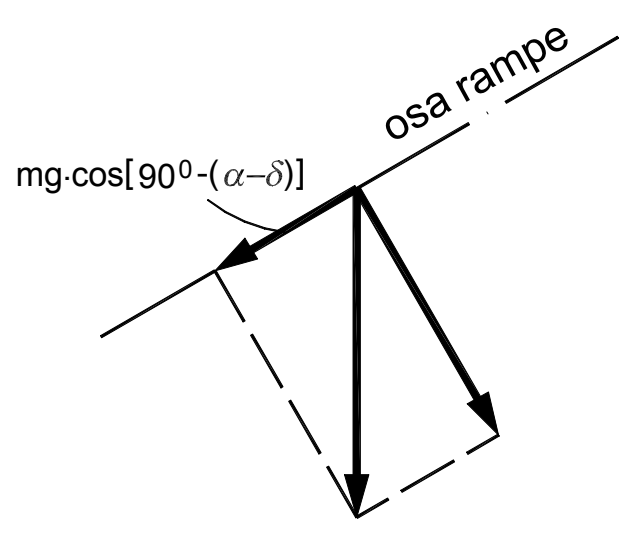

Sl. 6 - Projekcije sile težine na uzdužnu i poprečnu osu rampe

- $\mathrm{E}_{\mathrm{p} 1}^{(3)}$ - potencijalna energija lansirne rampe usled dejstva transverzalne sile je:

$$
E_{p 1}^{(3)}=\frac{1}{2} \int_{o}^{l} F_{t r .}(x, t) y \cdot d x=\frac{1}{2} a_{1} \int_{o}^{l} F_{t r .}(x, t) x d x
$$

a s obzirom na to da na lansirnoj rampi postoje tri polja, ona je određena izrazom:

$$
\begin{aligned}
& E_{p 1}^{(3)}=\left(E_{p 1}^{(3)}\right)_{1 \text { polje }}+\left(E_{p 1}^{(3)}\right)_{2 \text { polje }}+\left(E_{p 1}^{(3)}\right)_{3 \text { polje }}= \\
& =\frac{a_{1}}{4}\left[\rho A g(l-\xi)\left(\cos \alpha-\frac{u}{l} \sin \alpha\right)\right] . \\
& \cdot\left(l^{2}-\xi^{2}\right)+\frac{a_{1}}{4}\left[\rho A g(l-\xi)+m_{2} g\right] \\
& \left(\cos \alpha-\frac{u}{l} \sin \alpha\right) \cdot\left(\xi^{2}-l_{1}^{2}\right)+\frac{a_{1} l_{1}^{2}}{4} \\
& \left\{\left[\rho A g(l-\xi)+m_{2} g\right]\left(\cos \alpha-\frac{u}{l} \sin \alpha\right)-\right. \\
& -c a_{1} l_{1} \cos \theta-b \dot{y}_{B} \cos \theta
\end{aligned}
$$

gde je: $\mathrm{c}$ - krutost oslonca B (hidrocilindra), $b$ - koeficijent viskoznog trenja, $\mathrm{y}_{\mathrm{B}}$ - ugib rampe u tački B. 


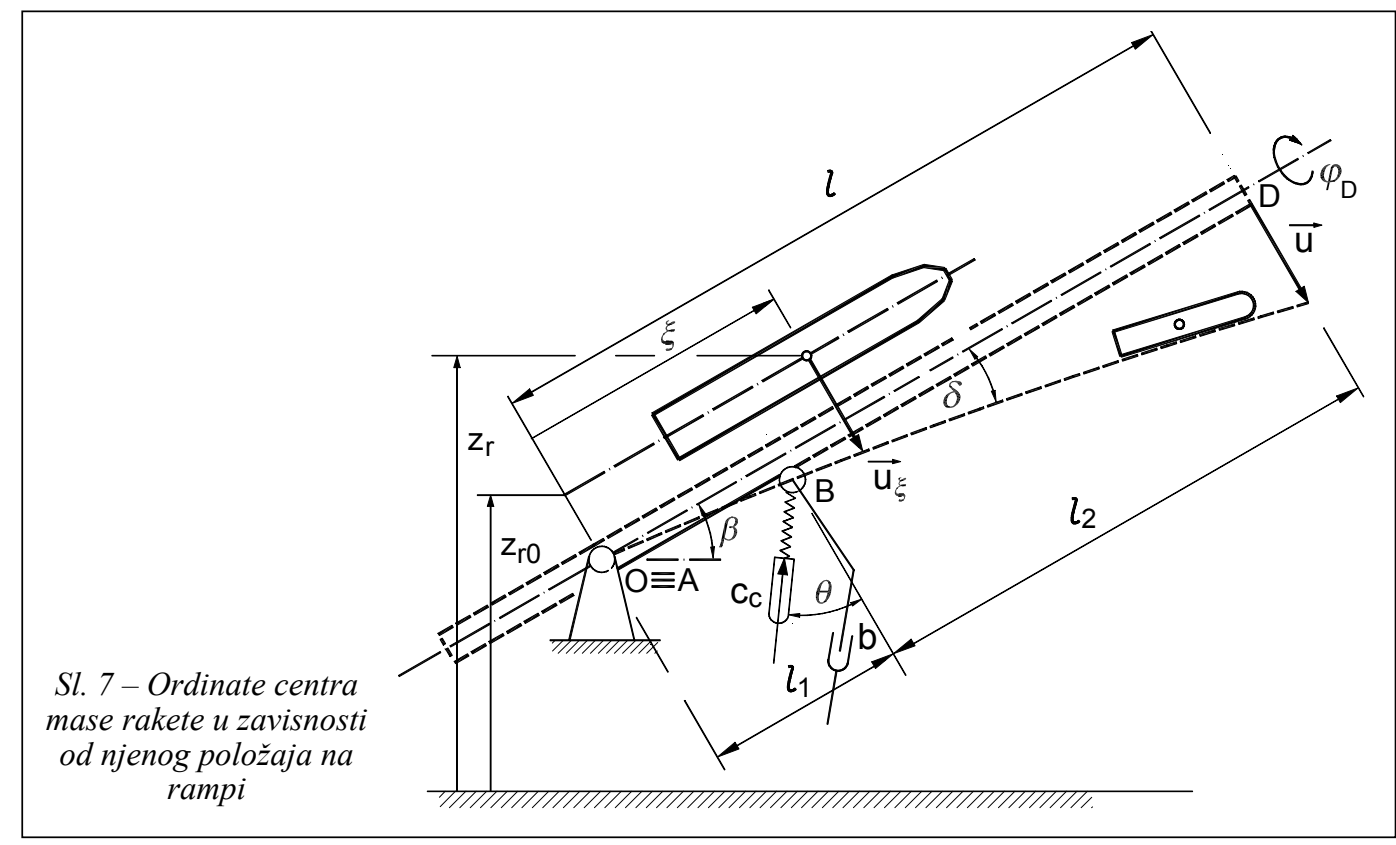

Potencijalna energija rakete

Potencijalna energija rakete ima oblik: $E_{p 2}=-m_{2} g\left(z_{r}-z_{r 0}\right)=m_{2} g\left(z_{r 0}-z_{r}\right)=$ $=m_{2} g\left(\frac{u}{l} \xi-\xi \sin \beta\right)$

gde su (sl. 7): $z_{r}-$ trenutna ordinata centra mase rakete, $Z_{\mathrm{r} 0}$ - početna trenutna ordinata centra mase rakete.

Izrazom (37) zanemaruje se uticaj rotacije lansirne rampe oko podužne ose na potencijalnu energiju rakete.

Potencijalna energija hidrocilindra

Potencijalna energija hidrocilindra (oslonca) ima oblik:

$$
E_{p 3}=-\frac{1}{2} c y_{B}^{2}-b \dot{y}_{B} \cdot y_{B}
$$

gde je: $\mathrm{c}$ - krutost oslonca B (hidrocilindra), b - koeficijent viskoznog trenja, ув - ugib rampe u tački $B$.
Konačno, ukupna potencijalna energija mehaničkog sistema (rampe, rakete i oslonca) iznosi:

$$
\begin{aligned}
& E_{p}=E_{p 1}+E_{p 2}+E_{p 3}=\frac{a_{1}}{4} \\
& {\left[\rho \operatorname{Ag}(l-\xi)\left(\cos \alpha-\frac{u}{l} \sin \alpha\right)\right] \cdot\left(l^{2}-\xi^{2}\right)+}
\end{aligned}
$$

$+\frac{a_{1}}{4}\left[\rho A g(l-\xi)+m_{2} g\right]\left(\cos \alpha-\frac{u}{l} \sin \alpha\right)$

$\left(\xi^{2}-l_{1}^{2}\right)+\frac{a_{1}}{4}\left[\rho A g(l-\xi)+m_{2} g\right]$

$$
\left(\cos \alpha-\frac{u}{l} \sin \alpha\right)\left(\xi^{2}-l_{1}^{2}\right)+\frac{a_{1} l_{1}^{2}}{4}
$$

$\left\{\begin{array}{l}{\left[\rho A g(l-\xi)+m_{2} g\right]\left(\cos \alpha-\frac{u}{l} \sin \alpha\right)-} \\ -c a_{1} l_{1} \cos \theta-b \dot{y}_{B} \cos \theta\end{array}\right\}+$

$$
+m_{2} g\left(\frac{u}{l} \xi-\xi \sin \beta\right)+C_{31} u^{2}+C_{32} u
$$


Generalisane nekonzervativne sile

Generalisanom silom $\mathrm{Q}_{\mathrm{i}}(\mathrm{i}=1,2, \ldots$, s), koja odgovara generalisanoj koordinati $\mathrm{q}_{\mathrm{i}}$, naziva se skalarna veličina određena odnosom elementarnog rada sila koje utiču na pomeranje mehaničkog sistema izazvano elementarnim pomeranjem koordinate $\mathrm{q}_{\mathrm{i}}$, prema veličini tog pomeranja, tj.:

$Q_{i}=\frac{\delta A_{q_{i}}}{\delta q_{i}}=\sum_{k=1}^{n} \vec{F}_{k} \cdot \frac{\partial \vec{r}_{k}}{\partial q_{i}}, \quad(i=1,2, \ldots, s)$,

$(k=1,2, \ldots, n)$

gde je:

$\mathrm{n}$ - broj materijalnih tačaka,

$\mathrm{s}$ - broj stepeni slobode kretanja,

$\overrightarrow{\mathrm{F}}_{\mathrm{k}}$ - rezultujuća aktivna sila koja deluje $\mathrm{u}$ k-toj tački sistema,

$\vec{r}_{\mathrm{k}}$ - radijus vektor materijalne tačke,

$\mathrm{q}_{\mathrm{i}}$ - generalisana koordinata.

Ukupni rad sila koje deluju na mehanički sistem na elementarnom pomeranju sistema je

$\delta A_{q_{i}}=\sum_{k=1}^{n} \vec{F}_{k} \cdot \delta \vec{r}_{k}$

gde je priraštaj radijus-vektora

$$
\begin{aligned}
& \delta \vec{r}_{k}=\sum_{k=1}^{n} \frac{\partial r}{\partial q_{i}} \cdot \delta \vec{q}_{k},(i=1,2, \ldots, s), \\
& (k=1,2, \ldots, n)
\end{aligned}
$$

uslovljen priraštajem generalisane koordinate $\delta \overrightarrow{\mathrm{q}}_{\mathrm{k}}$.

Generalisana sila može da se izrazi i preko projekcija sila na ose Dekartovog koordinatnog sistema

$$
\begin{aligned}
& Q_{i}=\sum_{k=1}^{n}\left(F_{k x} \frac{\partial x_{k}}{\partial q_{i}}+F_{k y} \frac{\partial y_{k}}{\partial q_{i}}+F_{k z} \frac{\partial z_{k}}{\partial q_{i}}\right), \\
& (i=1,2, \ldots, s),(k=1,2, \ldots, n),
\end{aligned}
$$

gde je:

$$
\begin{aligned}
& \vec{F}_{k}=F_{k x} \vec{i}+F_{k y} \vec{j}+F_{k z} \vec{k}, \\
& \frac{\partial \vec{r}_{k}}{\partial q_{i}}=\frac{\partial x_{k}}{\partial q_{i}} \vec{i}+\frac{\partial y_{k}}{\partial q_{i}} \vec{j}+\frac{\partial z_{k}}{\partial q_{i}} \vec{k}
\end{aligned}
$$

Ako sve veze materijalnog sistema nisu idealne, npr. ako postoje hrapave oslone površine, tada pri izračunavanju generalisane sile po prethodnoj formuli, pod silom $\vec{F}_{k}$, podrazumevamo ne samo aktivne sile nego i sile nastale trenjem.

Postupak za određivanje generalisanih sila je sledeći:

a) ako su sile koje deluju na sistem potencijalne, tada se generalisane sile određuju jednostavnije, na taj način što se uzima parcijalni izvod potencijalne energije sistema po odgovarajućoj generalisanoj koordinati sa suprotnim predznakom

$Q_{i}=-\frac{\partial E_{p}}{\partial q_{i}},(i=1,2, \ldots, s) ;$

b) najrasprostranjeniji način određivanja generalisanih sila je određivanje koeficijenata u izrazu za sumu elementarnih radova pri odgovarajućim generalisanim mogućim pomeranjima, a određivanje generalisanih sila izvodi se sledećim redosledom:

- utvrđuje se broj stepeni slobode (s) razmatranog sistema materijalnih tačaka i biraju odgovarajuće generalisane koordinate $\left(\mathrm{q}_{\mathrm{i}}\right)$; 

stema;

- prikazuju se sve aktivne sile si-

- ako sve veze nisu idealne, aktivnim silama dodaju se i odgovarajuće reakcije veze (npr. sile trenja);

- daje se nezavisno generalisano moguće pomeranje sistema $\left(\mathrm{q}_{\mathrm{i}}\right)$, jednako broju generalisanih koordinata, odnosno broju stepeni slobode sistema;

- za određivanje generalisane sile $\mathrm{Q}_{\mathrm{i}}$ odgovarajuće i-te generalisane koordinate $\left(\mathrm{q}_{\mathrm{i}}\right)$ treba izračunati sumu radova svih aktivnih sila, uključujući i reakcije veza koje nisu idealne na generalisanom pomeranju $\left(\delta \mathrm{q}_{\mathrm{i}}\right)$. Pri tome, treba smatrati da su sva ostala generalisana moguća pomeranja $\left(\delta q_{1}, \delta q_{2}, \delta q_{3}, \ldots, \delta q_{i-1}, \delta q_{i+1}, \delta q_{s}\right)$ jednaka nuli, tj.:

$$
\begin{aligned}
& \delta q_{1} \neq 0 ; \quad \delta q_{1}=\delta q_{2}=\delta q_{3}= \\
& =, \ldots,=\delta q_{i-1}=\delta q_{i+1}=\delta q_{s}=0
\end{aligned}
$$

Tada je generalisana sila $Q_{i}$ jednaka koeficijentu pri $\delta q_{i} \neq 0$. Analogno se određuju i sve ostale generalisane sile.

Za slučaj da je kod mehaničkog sistema lakše odrediti snagu, generalisana sila se određuje kao odnos snage svih sila koje deluju na mehanički sistem pri mogućoj generalisanoj brzini $\dot{\mathrm{q}}_{\mathrm{k}}$ prema toj generalisanoj brzini

$$
\begin{aligned}
& Q_{i}=\frac{P_{i}}{\dot{q}_{k}} \\
& P_{i}=\sum_{i=1}^{n} P_{i k}=\sum_{i=1}^{n} P_{i} \frac{\partial \vec{r}_{i}}{\partial q_{k}} \dot{q}_{k}=\dot{q}_{k} \sum_{i=1}^{n} P_{i} \frac{\partial \vec{r}_{i}}{\partial q_{k}}
\end{aligned}
$$

$$
Q_{i}=\sum_{i=1}^{n} F_{i} \frac{\partial \vec{r}_{i}}{\partial q_{k}}
$$

sledi $P_{i}=\sum_{i=1}^{n} P_{i k}=Q_{i} \cdot \dot{q}_{i}$ odnosno

$Q_{i}=\frac{P_{i}}{\dot{q}_{k}}=\frac{\sum_{i=1}^{n} P_{i k}}{\dot{q}_{k}}$

\section{Rad nekonzervativnih sila}

Potražimo varijacije virtualnog rada i generalisane sile za generalisane koordinate $\xi, u$ i $\varphi$.

- Varijacija virtualnog rada i generalisana sila $\mathrm{Q}_{\xi}$, pri virtualnom pomeranju $\xi$, iznose:

$\delta A_{\xi}=F_{p} \delta \xi-F_{\mu} \delta \xi-F_{o t . v a z .} \delta \xi$

$Q_{\xi}=\frac{\delta A_{\xi}}{\delta \xi}=F_{p}-F_{\mu}-F_{o t . v a z .}$

gde su: $F_{p}$ - sila potiska raketnog motara, $\mathrm{F}_{\mu}$ - otpor viskoznog trenja i $\mathrm{F}_{\text {ot.vaz. }}$ - otpor vazduha.

Otpor vazduha je:

$$
\begin{aligned}
& F_{\text {ot.vaz. }}=\frac{1}{2} \rho C A v_{r}^{2}=\frac{1}{2} \rho C A \\
& {\left[\dot{\xi}^{2}+\frac{1}{l^{2}}(\dot{\xi} u+\xi \dot{u})^{2}+\frac{1}{l^{2}}(\dot{\xi} u \varphi+\xi \dot{u} \varphi+\xi u \dot{\varphi})^{2}\right]}
\end{aligned}
$$

U prethodnom izrazu je: $\rho$ - gustina sredine kroz koju se kreće raketa, C bezdimenzionalni koeficijent zavisan od 
oblika rakete, A - površina poprečnog preseka rakete upravna na vektor brzine.

Otpor viskoznog trenja (sila trenja rakete o lansirnu rampu) jeste:

$$
F_{\mu}=\mu m_{r} g \cos \alpha
$$

gde je $\mu$ - koeficijent trenja rakete o lansirnu rampu.

Sila potiska raketnog motara je:

$$
\begin{aligned}
& F_{p}=k t, \text { za } 0<t \leq t_{1}, \text { odnosno } \\
& F_{p}=\text { const., za } t \geq t_{1}
\end{aligned}
$$

Pri temperaturi vazduha $\mathrm{t}=15^{\circ} \mathrm{C}$, brzina narastanja potisne sile $\mathrm{u}$ funkciji vremena je: $k=582130,98 \frac{\mathrm{N}}{\mathrm{s}}, \mathrm{tj} ., \beta=89,99^{\circ}$ (sl. 8)

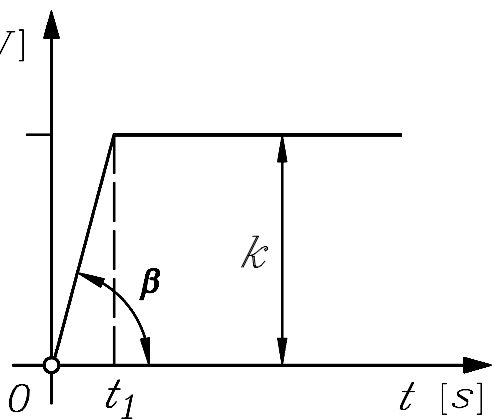

Sl. 8 - Promena sile potiska u f-ji vremena

- Varijacija virtualnog rada i generalisana sila $\mathrm{Q}_{\mathrm{u}}$, pri virtualnom pomeranju $\mathrm{u}$, iznose:

$$
\delta A_{u}=-F_{c} \cos \theta \cdot \delta u_{B}=-F_{c} \cos \theta \cdot \frac{l_{1}}{l} \delta u
$$

$Q_{u}=\frac{\delta A_{u}}{\delta u}=-F_{c} \frac{l_{1}}{l} \cos \theta$
- Varijacija virtualnog rada i generalisana sila $\mathrm{Q}_{\varphi}$, pri virtualnom pomeranju $\varphi$, iznose:

$\delta A_{\varphi_{D}}=0$

$Q_{\varphi_{D}}=\frac{\delta A_{\varphi_{D}}}{\delta \varphi_{D}}=0$

\section{Diferencijalne jednačine kretanja mehaničkog sistema}

$\mathrm{Za}$ izvođenje diferencijalnih jednačina kretanja koriste se Lagranžove jednačine druge vrste:

$\frac{d}{d t}\left(\frac{\partial E_{k}}{\partial \dot{q}_{i}}\right)-\frac{\partial E_{k}}{\partial q_{i}}+\frac{\partial E_{p}}{\partial q_{i}}=Q_{i}^{N}, i=1,2,3$.

Dobijeni matematički model predstavlja sistem od tri nelinearne, nehomogene diferencijalne jednačine drugog reda. Dati sistem diferencijalnih jednačina je blizak sistemima Ljapunova, a rešava se razlaganjem malih parametara $u$ vidu reda, pri čemu se od običnih diferencijalnih jednačina prelazi na sistem parcijalnih diferencijalnih jednačina po izabranim promenljivim.

Međutim, navedeni sistem se brže i jednostavnije rešava korišćenjem diskretnih numeričkih metoda, koje se veoma efikasno realizuju na računarima. $\mathrm{Za}$ ovakve sisteme diferencijalnih jednačina, preporučuje se metoda Runge-Kuta. Iz tog razloga potrebno je sistem diferencijalnih jednačina uz prethodnu smenu:

$$
\begin{aligned}
& x_{1}=\xi, \quad x_{2}=\dot{\xi}, \quad x_{3}=u, \quad x_{4}=\dot{u}, \quad x_{5}=\varphi, \\
& x_{6}=\dot{\varphi}
\end{aligned}
$$


napisati u matričnom obliku:

$$
\begin{aligned}
& \|A(\xi, u, \varphi)\|\left\{\begin{array}{l}
\ddot{\xi} \\
\ddot{u} \\
\ddot{\varphi}
\end{array}\right\}+\|B(\xi, u, \varphi)\|\left\{\begin{array}{c}
\dot{\xi} \\
\dot{u} \\
\dot{\varphi}
\end{array}\right\}+ \\
& +\|C(\xi, u, \varphi)\|\left\{\begin{array}{l}
\xi \\
u \\
\varphi
\end{array}\right\}=\{D(\xi, u, \varphi, \dot{\xi}, \dot{u}, \dot{\varphi})\}
\end{aligned}
$$

Ovaj sistem se transformiše na sistem od šest diferencijalnih jednačina prvog reda, pogodan za numeričko rešavanje programskim paketom FORTRAN. Numerička analiza ovog problema je urađena za konkretnu raketu.

\section{Numerički rezultati i diskusija}

Numerička analiza je vršena za slučaj kada je hidrocilindar zamenjen silom otpora linearno proporcionalnom prvom stepenu brzine tačke B (slika 1).

Grafički pregled dobijenih rezultata u ovom radu, kao i nekih rezultata proizašlih iz prethodnih istraživanja autora prikazan je na slikama 9-14:

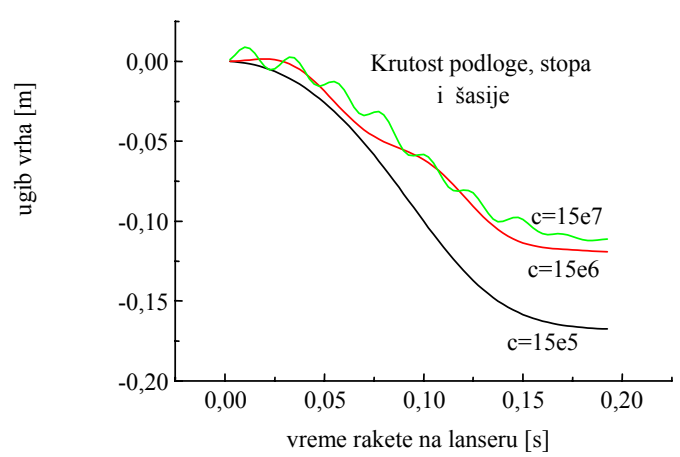

Sl. 9 - Simulacija procesa lansiranja za različite krutosti podloge, stopa i šasije

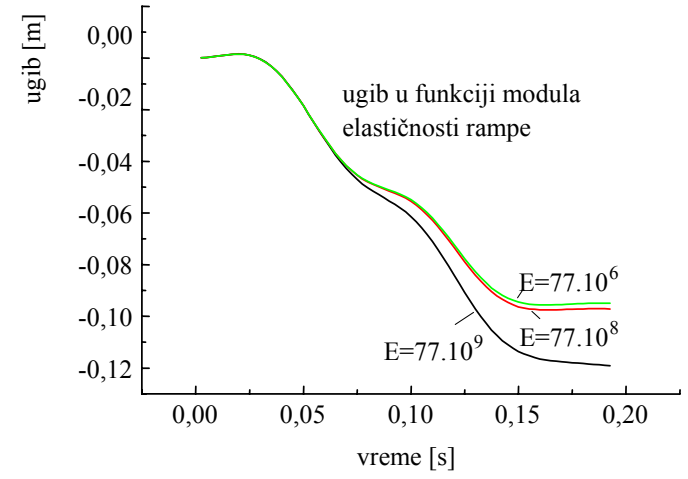

Sl. 10 - Simulacija procesa lansiranja za različite vrednosti modula elastičnosti lansirne rampe

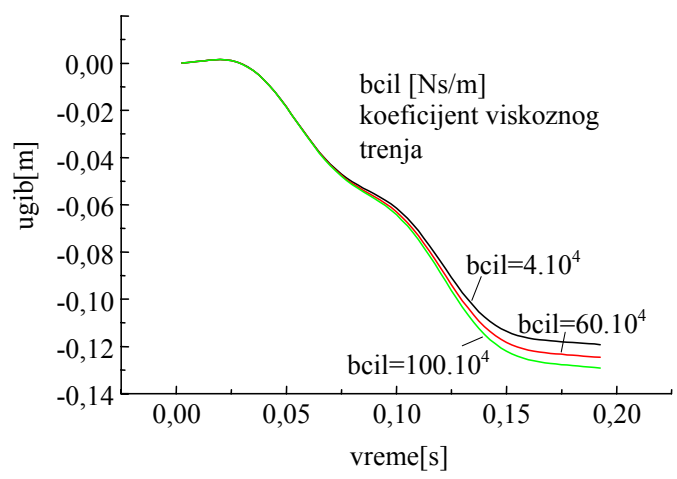

Sl. 11 - Simulacija procesa lansiranja za različite vrednosti koeficijenta viskoznog trenja hidrocilindra

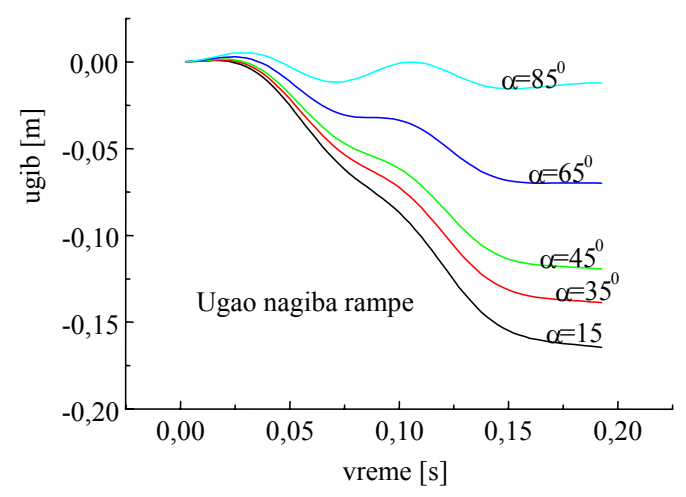

Sl. 12 - Simulacija procesa lansiranja za različite vrednosti ugla nagiba lansirne rampe 


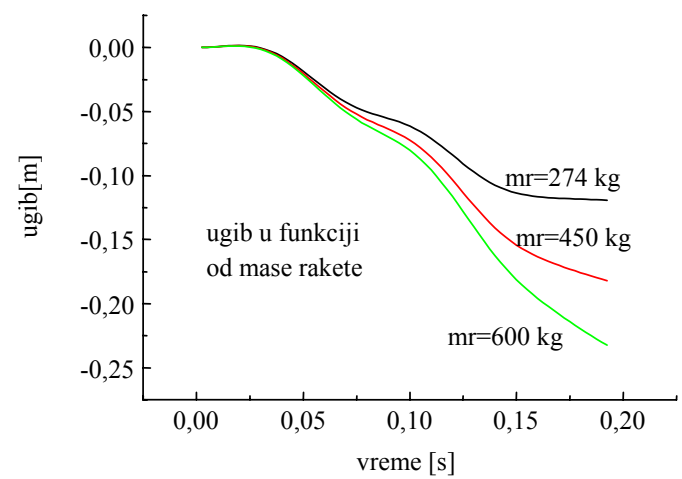

Sl. 13 - Simulacija procesa lansiranja za različite vrednosti težine rakete

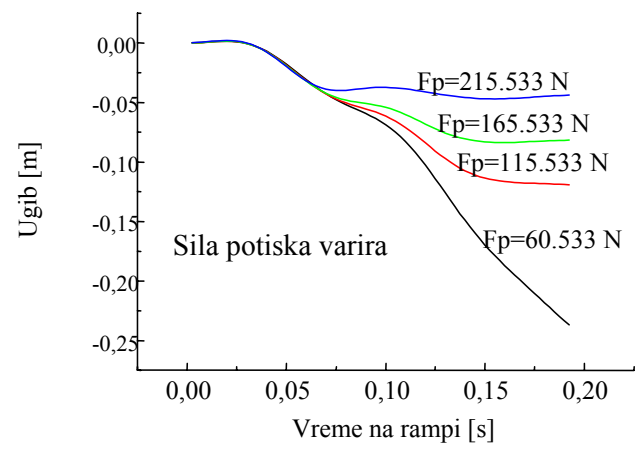

Sl. 14 - Simulacija procesa lansiranja za različite vrednosti sile potiska raketnog motora

\section{Zaključak}

Ustaljenom procedurom postavljanja diferencijalnih jednačina može se opisati realni mehanički sistem, kao što je raketni lanser, a što je neophodno pri istraživanju i analizi dinamičkih parametara konstrukcije lansirne rampe na vozilu točkašu. Mehaničko-matematičkim modeliranjem i simulacijom na računaru može da se utvrdi uticaj svakog konstrukcionog i eksploatacionog parametra na ponašanje raketne rampe, što je od posebnog značaja u fazi projektovanja ili modifikacije konstrukcije. To je od velike važnosti, jer se time optimizira konstrukcija rampe i konstrukcija samog raketnog lansera, što je veoma bitno za borbena dejstva.

S obzirom na to da se rešenje matematičkog modela može primeniti u analizi uticaja konkretnih konstrukcijskih paramatara na određene osobine lansirne rampe, a time i lansera u celini, iz ovog dela istraživanja mogu se izvesti sledeći zaključci:

- rad daje sveobuhvatnu dinamičku analizu lansirne rampe, kao i analizu uticaja rampe na čitavu konstrukciju lansera;

- primenom Lagranžovih jednačina druge vrste, prikazani sistem od tri nelinearne nehomogene jednačine s promenljivim koeficijentima napisan je u matričnom obliku;

- verifikacija teoretskih rezultata izvršena je na konkretnom raketnom lanseru i lansirnoj rampi;

- jedna od osnovnih postavki dinamičkog modela jeste da posle izletanja rakete $\mathrm{s}$ lansirne rampe, raketni sistem prigušeno osciluje, a poremećaji pri startu rakete predstavljaju početne uslove oscilovanja;

- ugao nagiba lansirne rampe ima znatan uticaj na tok procesa oscilovanja raketnog sistema, posebno na ugib rampe, ali u manjoj meri nego krutost oslonca;

- smanjenjem vrednosti koeficijenta viskoznog trenja hidrocilindra povećava se ugib vrha lansirne rampe;

- krutost hidrocilindra u jednom određenom području dominantno utiče na ugib lansirne rampe; 
- sila potiska rakete ne utiče znatno na ugib vrha lansirne rampe za razliku od modula elastičnosti lansirne rampe koji bitno utiče na ugib njenog vrha. To upućuje na zaključak da treba ispitati mogućnost primene i drugih materijala za izradu lansirne rampe osim čeličnih (na primer, duraluminijuma, koji ima gustinu, odnosno težinu koja je skoro tri puta manja od čelika, a mehaničke karakteristike koje odgovaraju čeliku srednjeg kvaliteta).

$\mathrm{U}$ radu je, takođe, razmatrana mogućnost ugradnje oruđa velikog kalibra na šasiju terenskog vozila $8 \times 8$ serijske proizvodnje radi analize utvrđivanja procene prihvatanja opterećenja šasije i sistema za oslanjanje $u$ uslovima gađanja.

- Takođe, razmatrana je mogućnost ugradnje dodatnog elastičnog rama i stopa. Izvršene su odgovarajuće analize primenom metode konačnih elemenata. Rezultati proračuna potvrđeni su eksperimentima.

- U radu su eksperimentalno potvrđeni rezultati dinamičke analize ponašanja elastično oslonjene nadgradnje terenskih vozila pod dejstvom impulsnog opterećenja. Analize su vršene na matematičko-dinamičkom modelu dva sredstva ratne tehnike: raketnog lansera i haubice $155 \mathrm{~mm}$.

\section{Literatura:}

[1] Timošenko, S. P., Jang, D. H.: Teorija oscilacija - primene u tehnici, Građevinska knjiga Beograd, 1966.

[2] Светлицкий, В. А.: Динамика старта летательных аппаратов, Москва „Наука“, Главная редакция физикоматематической литературы, 1986.

[3] Шелмич, Р.: Динамические нагрузки и устойчивость автокрана на упругом основании, „Строительные и дорожные машины“, Москва 4/1996., пп. 32-33.

[4] Šelmić, R. R., Đurković, P. V.: Dinamička analiza lansirnog sistema, Istraživanje i razvoj mašinskih elemenata i sistema IRMES 2000, Naučno-stručni skup, Kotor, 14. i 15. septembar 2000. str. 309-314.

[5] Šelmić, R., Đurković, V.: Analiza dinamičkih parametara lansirne rampe pri lansiranju letelice, Naučno-tehnički pregled, Vol. L, br. 3/2000, str. 40-44.

[6] Đurković, P. V., Šelmić, R. R.: Analiza dinamike lansera na mehaničkom modelu sa elastičnim osloncima i deformabilnom rampom, Naučnotehnički pregled, vol. LI, br. 5 . pp. 54-63, Beograd, 2001

[7] Selmić, R., Đurković, V.: Analiza dinamičke stabilnosti raketnog lansera, Istraživanje i razvoj mašinskih elemenata i sistema - IRMES, Jahorina 2002, Zbornik radova, str. 505-510.

[8] Mijailović, R., Šelmić, R. R., Đurković, P. V.: Analiza parametara uticajnih na dinamičku stabilnost raketnog lansera, Istraživanje i razvoj mašinskih elemenata i sistema IRMES 2004, Naučno-stručni skup, Kragujevac, 16. i 17. septembar 2004, str. 221-226.

[9] Tasić, M., Đurković, P. V., Pantić, M.: Uticaj impulsnog opterećenja duž podužne ose na oscilovanje nosećeg rama vozila, Asocijacija za dizajn, elemente i konstrukcije ADE$\mathrm{KO}$, Istraživanje i razvoj mašinskih elemenata i sistema IRMES 2006, Naučno-stručni skup, Banja Luka 21. i 22. septembar 2006, str. 287-292.

[10] Šelmić, R. R., Đurković, P. V.: O linearizaciji nelinearnih diferencijalnih jednačina kretanja mehaničkih sistema, Asocijacija za dizajn, elemente i konstrukcije ADEKO, Istraživanje i razvoj mašinskih elemenata i sistema IRMES 2006, Naučno-stručni skup, Banja Luka 21. i 22. septembar 2006, str. 107-112.

[11] Tasić, M., Đurković, P. V., Pantić, M.: Eksperimentalno utvrđivanje pomeranja elastično oslonjenog rama vozila $u$ uslovima impulsnog opterećenja, XXXIII simpozijum o operacionim istraživanjima, SYM - OP - IS 2006, Naučno-stručni skup, Banja Koviljača od 03. do 06. oktobra 2006, str. 633-636.

[12] Tasić, M., Pantić, M., Đurković, P. V.: Analiza elastično oslonjenog rama vozila sa nadgradnjom, JUMV - Jugoslovensko društvo za motore i vozila, međunarodni naučno-stručni skup sa izložbom, XXI nauka i motorna vozila, Beograd od 23. do 25. aprila 2007. 